\title{
High insulin enhances neutrophil transendothelial migration through increasing surface expression of platelet endothelial cell adhesion molecule- 1 via activation of mitogen activated protein kinase
}

\author{
M. Okouchi, N. Okayama, S. Imai, H. Omi, M. Shimizu, T. Fukutomi, M. Itoh \\ First Department of Internal Medicine, Nagoya City University Medical School, Nagoya, Japan
}

\begin{abstract}
Aims/hypothesis. There is increasing evidence that hyperinsulinaemia is linked with the development of atherosclerosis in patients with diabetes. However, the mechanisms by which hyperinsulinaemia causes accelerated atherosclerosis, especially with respect to leukocytes transendothelial migration, are poorly understood. We examined whether hyperinsulinaemia directly affects neutrophil transendothelial migration and surface expression of related endothelial adhesion molecules. Methods. Experiments on the transmigration of neutrophils from healthy volunteers and from patients with Type II (non-insulin-dependent) diabetes mellitus across human umbilical vein endothelial cells cultured in insulin-rich medium using cell-culture inserts were carried out. Migrated neutrophils were quantified by measuring their myeloperoxidase activities, and the surface expression of endothelial adhesion molecules was examined using an enzyme immunoassay.

Results. High insulin (over $50 \mu \mathrm{U} / \mathrm{ml}$ for $24 \mathrm{~h}$ ) enhanced neutrophil transendothelial migration in a
\end{abstract}

dose-dependent manner. This was associated with increased expression of platelet endothelial cell adhesion molecule-1 (PECAM-1) but not of intercellular adhesion molecule-1 (ICAM-1), P-selectin or E-selectin. Both phenomena were attenuated by pretreatment with a tyrosine kinase inhibitor, especially a mitogenactivated protein kinase inhibitor, but not by inhibitors of other second messengers. In addition, a mitogenactivated protein kinase activator, anisomycin, by itself enhanced both neutrophil transendothelial migration and PECAM-1 expression within $3 \mathrm{~h}$ in a dosedependent manner. Pretreatment with nitric oxide synthase inhibitors had no effect on these events.

Conclusion/interpretation. These results suggest that hyperinsulinaemia could accelerate atherosclerosis by directly enhancing neutrophil transendothelial migration through increasing endothelial PECAM-1 expression via mitogen-activated protein kinase activation. [Diabetologia (2002) 45:1449-1456]

Keywords Insulin resistance, hyperinsulinaemia, atherosclerosis, endothelial cells, adhesion molecules.
Received: 21 January 2002 / Revised: 8 May 2002

Published online: 10 August 2002

C) Springer-Verlag 2002

Corresponding author: M. Okouchi, MD, First Department of Internal Medicine, Nagoya City University Medical School, 1 Kawasumi, Mizuho-cho, Mizuho-ku, Nagoya 467-8601, Japan. E-mail: okochi@med.nagoya-cu.ac.jp

Abbreviations: PECAM-1, Platelet endothelial cell adhesion molecule-1; ICAM-1, intercellular adhesion molecule-1; AMI, acute myocardial infarction; MPO, myeloperoxidase; MAP, mitogen activated protein; PI-3, phosphatidylinositol-3; PKC, protein kinase C; HUVEC, human umbilical vein endothelial cells; PMN, polymorphonuclear neutrophils (leukocytes); HBSS, Hanks balanced salt solution; NOS, nitric oxide synthase; ROS, reactive oxygen species.
There is increasing evidence that hyperinsulinaemia is linked with the development of atherosclerosis in patients with diabetes $[1,2,3]$. Atherosclerosis is accompanied by the accelerated formation of plaques on the vascular wall, which can suddenly cause disruption with thrombosis, leading to acute myocardial infarction (AMI) and stroke [4]. Diabetic patients have a high incidence of microvascular and macrovascular complications mediated by atherosclerosis [5]. However, the United Kingdom Prospective Diabetes Study (UKPDS) and other similar studies indicated that intensive control of blood glucose in diabetic patients prevents and/or slows the progression of microvascu- 
lar complications, but has little effect on macrovascular complications including AMI $[6,7,8]$. These results further support the idea that hyperinsulinaemia, but not hyperglycaemia, influences the increased development of AMI and stroke in patients with diabetes. Understanding the mechanisms linking hyperinsulinaemia with accelerated atherosclerosis could be helpful in preventing excessive atherosclerotic complications in diabetic patients.

Recently, inflammation in the vascular wall has emerged as a major culprit in the development of atherosclerosis [9]. Although the crucial early events in vascular inflammation in atherosclerosis are the adhesion and transendothelial migration of leukocytes, especially neutrophils, which are the first immune cells to arrive at the inflammatory site, seem to play important roles in the initiation of both events [10]. In addition, recent reports suggested that neutrophils were occasionally found in disrupted plaques [11], and myeloperoxidase (MPO), the enzyme of leukocytes (including neutrophils) which promotes oxidation of lipoproteins, was present in atherosclerotic plaques [12]. These observations support the importance of neutrophil transendothelial migration in the development and disruption of atherosclerotic plaques [13]. Therefore, we focused on the correlation between hyperinsulinaemia and neutrophil transendothelial migration.

It is well known that leukocyte transendothelial migration is regulated by several endothelial adhesion molecules, especially platelet endothelial cell adhesion molecules-1 (PECAM-1). A number of studies showed that an antibody against PECAM-1 blocked the transendothelial migration of leukocytes into inflammatory sites [14, 15] and that PECAM-1-deficient mice had defective neutrophil transendothelial migration [16]. PECAM-1 is a $130-\mathrm{kD}$ member of the immunoglobulin gene superfamily and is expressed constitutively on endothelial cell surfaces [14]. We therefore investigated whether high insulin changes PECAM-1 expression on endothelial cell surfaces and its correlation with neutrophil transendothelial migration.

Many reports indicate that insulin has two different activities. It can be either atherogenic through a mitogen-activated protein (MAP) kinase pathway or antiatherogenic through a phosphatidylinositol-3 (PI-3) kinase pathway which promotes the production of the vasodilator nitric oxide by endothelial cells $[17,18$, 19]. We have reported previously that high insulin enhances neutrophil-endothelial cell adhesion through a protein kinase $\mathrm{C}$ (PKC) and MAP kinase pathways [20]. Based on these data, we evaluated the intracellular mechanisms, including the participation of nitric oxide, associated with high insulin-mediated neutrophil transendothelial migration and surface expression of endothelial PECAM-1.

\section{Materials and methods}

This study was carried out in accordance with the Declaration of Helsinki as revised in 1996.

Cell culture. Human umbilical vein endothelial cells (HUVEC; Kurabo, Osaka, Japan) were cultured in $25 \mathrm{~cm}^{2}$ collagen I-coated flasks (Becton and Dickinson, Bedford, Mass., USA) at $37^{\circ} \mathrm{C}$ in a $100 \%$ humidified atmosphere containing $5 \% \mathrm{CO}_{2}$, and expanded after brief trypsinization using $0.25 \%$ trypsin in PBS containing $0.02 \%$ EDTA. Cells were cultured in CS-C medium (45\% DMEM, 45 \% Ham's F12 medium, 10\% foetal bovine serum, $10 \mathrm{ng} / \mathrm{ml}$ acidic-fibroblast growth factor, $50 \mathrm{U} / \mathrm{ml}$ heparin, and $15 \mathrm{mmol} / \mathrm{l}$ HEPES; Cell Systems, Kirkland, Wash., USA) containing antibiotic-antimicotic (Gibco BRL, Grand Island, N.Y., USA). Culture medium was replaced twice weekly, and cells were subcultured when confluent. Passage 4 cells were used for all the experiments.

Neutrophil isolation. This study protocol was approved by the ethics committee in Kasadera Hospital, Nagoya, Japan. After informed consent, human neutrophilic polymorphonuclear leukocytes (PMN) were isolated from venous blood of healthy non-smoking volunteers and Type II diabetic patients with hyperinsulinaemia in Kasadera Hospital using standard dextran sedimentation and gradient separation on Histopaque 1077 (Sigma, St. Lois, Mo., USA). This procedure yields a PMN population which is $98 \%$ pure as judged by acetic acid-crystal violet staining and 95 to $98 \%$ viable by trypan blue exclusion. No platelet contamination was seen in the isolated PMN examined using a microscope.

Assay of neutrophil transmigration across HUVEC. A neutrophil transendothelial migration assay was done according to a method described previously [21] with a minor modification. For transmigration experiments, HUVEC were cultured on human fibronectin-coated cell culture inserts $(3.0 \mu \mathrm{m}$ pore size; Becton Dickinson, Bedford, Mass., USA) in 24-well plates. They were incubated for 24 to $72 \mathrm{~h}$ at $37^{\circ} \mathrm{C}$ with or without human regular insulin (Novolin R, Novo-Nordisk, Bagsvaard, Denmark) and/or various chemical agents. The surface area of each insert was $0.33 \mathrm{~cm}^{2}$, containing approximately $16000 \mathrm{en}-$ dothelial cells. After treatment, culture medium in both the inserts and wells was replaced with Hanks' balanced salt solution (HBSS, Gibco BRL), and neutrophils (exactly $1 \times 10^{5}$ cells) were added to each upper compartment (insert) and allowed to migrate across HUVEC monolayers to the lower compartment (well) for $1 \mathrm{~h}$ at $37^{\circ} \mathrm{C}$. To stimulate neutrophil migration, a chemotactic peptide, formyl-methionyl-leucyl-phenylalanine $\left(10^{-7} \mathrm{~mol} / \mathrm{l}\right.$, Sigma) was added to the lower compartments before adding neutrophils. Neutrophil migration was stopped by removing the inserts from the wells and then the 24-well plates were centrifuged at $1500 \mathrm{rpm}$ for $5 \mathrm{~min}$. Migrated neutrophils in the wells were quantified with a myeloperoxidase (MPO) assay using a previously reported method [20] in which the $\mathrm{H}_{2} \mathrm{O}_{2}$-dependent oxidation of $3,3^{\prime}, 5,5^{\prime}$-tetramethylbenzidine (Sigma) was measured. Neutrophil migration was expressed as the ratio of MPO activity of migrated neutrophils to that of the total neutrophils $\left(1 \times 10^{5}\right.$ cells $)$.

Assay of surface expression of endothelial PECAM-1. Surface expression of endothelial PECAM-1 was measured using a method reported previously [20]. Briefly, after treatment of cells with or without human regular insulin in collagen I-coated 24-well plates, cells were fixed for $10 \mathrm{~min}$ at room temperature with $1 \%$ paraformaldehyde in PBS. After three washes with $1 \mathrm{ml}$ HBSS:PBS $(1: 1)$, cells were incubated for $60 \mathrm{~min}$ at 
$37^{\circ} \mathrm{C}$ with an anti-PECAM-1 antibody $(\mathrm{Ab})$ (primary antibody; diluted 1:100; Sigma) in HBSS:PBS containing 5\% foetal calf serum (FCS). Cells were washed twice with $0.5 \mathrm{ml}$ HBSS:PBS and incubated for $60 \mathrm{~min}$ at $37^{\circ} \mathrm{C}$ with horseradish peroxidaseconjugated goat anti-mouse IgG (diluted 1:2500; Sigma) in HBSS:PBS containing 5\% FCS. Cells were then washed three times with $0.5 \mathrm{ml} \mathrm{HBSS}$ :PBS and incubated for $60 \mathrm{~min}$ at $37^{\circ} \mathrm{C}$ in the dark with $0.25 \mathrm{ml} 0.003 \% \mathrm{H}_{2} \mathrm{O}_{2}$ plus $0.1 \mathrm{mg} / \mathrm{ml}$ $3,3^{\prime}, 5,5^{\prime}$-tetramethylbenzidine as a substrate. The reaction was stopped by adding $75 \mu \mathrm{l}$ of $8 \mathrm{~N} \mathrm{H}_{2} \mathrm{SO}_{4}$, and the samples were transferred to 96 -well plates which were read at $450 \mathrm{~nm}$ on a plate reader. Controls consisted of cells stained only with secondary antibody.

Immunoblotting. The expression of endothelial PECAM-1 phosphorylation was analysed using a Western blotting method. After treatment of cells with or without human regular insulin in collagen I-coated $6 \mathrm{~cm}$ tissue culture dishes (Becton and Dickinson, Bedford, Mass., USA), cells were lysed with a lysis buffer containing $50 \mathrm{mmol} / \mathrm{l}$ Tris- $\mathrm{HCl} \mathrm{pH} 7.5,120 \mathrm{mmol} / \mathrm{l}$ $\mathrm{NaCl}, 2 \mathrm{mmol} / \mathrm{l}$ EGTA, $10 \mathrm{mmol} / \mathrm{l} \mathrm{NaF}, 40 \mathrm{mmol} / \mathrm{l} \beta$-glycerophosphate, $1 \%$ Triton $\mathrm{X}-100,1 \mathrm{mmol} / \mathrm{l}$ dithiothreitol, $10 \mu \mathrm{g} / \mathrm{ml}$ aprotinin, and $1 \mathrm{mmol} / \mathrm{l}$ phenylmethylsulfonyl fluoride. The lysates were centrifuged at $15000 \mathrm{rpm}$ for $20 \mathrm{~min}$ at $4^{\circ} \mathrm{C}$. Proteins in the lysates were separated in $6 \%$ sodium dodecyl sulphate-polyacrylamide gels (SDS-PAGE) and transferred to nitrocellulose membranes (Amersham) according to standard procedures. The membranes were blocked overnight with $5 \%$ non-fat milk containing $0.05 \%$ Tween 20 in PBS. To detect the expression of PECAM-1 phosphorylation, the membranes were incubated for $1 \mathrm{~h}$ at room temperature with anti-phosphotyrosine Ab (4G10) (primary antibody; diluted 1:5000; Upstate Biotechnology, Lake Placid, N.Y., USA) followed by horseradish-peroxidase-conjugated goat anti-mouse IgG Ab (secondary Ab; diluted 1:5000; Upstate Biotechnology, Lake Placid, N.Y., USA). Antibody binding was detected using the enhanced chemiluminescence detection system (Amersham) according to the manufacturer's instructions.

Treatment protocols. Before a transmigration or surface expression assay, HUVEC monolayers were preincubated for $3 \mathrm{~h}$ with or without the following agents; intracellular second messenger inhibitors: a classical protein kinase C (PKC) inhibitor, Gö6976 (10 nmol/l; Calbiochem, San Diego, Calif., USA), a broad PKC

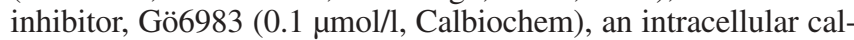
cium chelator, 3,4,5-trimethoxybenzoic acid 8-(diethyamino)octyl ester (TMB-8) (0.1 mmol/l; Sigma), a protein kinase G (PKG) inhibitor, KT5823 (0.5 $\mu \mathrm{mol} / \mathrm{l}$; Calbiochem), a tyrosine kinase inhibitor, genistein ( $5 \mu \mathrm{mol} / \mathrm{l}$; Calbiochem), a protein $\mathrm{ki}$ nase A (PKA) inhibitor, $\mathrm{N}$-[2-(p-bromo-cinnamylamino) ethyl]5-isoquinolinesulfomide.2HCL (H-89) (0.1 $\mu \mathrm{mol} / \mathrm{l}$; Seikagaku, Tokyo, Japan), a MAP kinase inhibitor, PD98059 (10 $\mu \mathrm{mol} / \mathrm{l}$; Calbiochem), and a PI 3-kinase inhibitor, wortmannin $(10 \mathrm{nmol} / \mathrm{l}$; Calbiochem); a MAP kinase activator (selective for the JNK and p38 family of MAP kinase); anisomycin (10 nmol/l-10 $\mu \mathrm{mol} / \mathrm{l}$; Calbiochem) and nitric oxide synthase (NOS) inhibitors: ${ }_{N}{ }^{\mathrm{G}}$-Nitro-L-arginine methyl ester hydrochloride (L-NAME) (30 $\mu \mathrm{mol} / \mathrm{l}$; Dojindo, Kumamoto, Japan) and $N^{5}$-(1-Iminoethyl)L-ornithine dihydrochloride (L-NIO) ( $3 \mu \mathrm{mol} / \mathrm{l}$; Dojindo, Kumamoto, Japan). The doses of the second messenger inhibitors were determined from their $\mathrm{IC}_{50}$ values.

Statistical analysis. All experiments were performed in triplicate with four different endothelial cell preparations. All values are expressed as means \pm SEM. Data were analysed using a one-way ANOVA with a Fisher's Exact test for multiple comparisons. A $p$ value of less than 0.05 was considered significant.

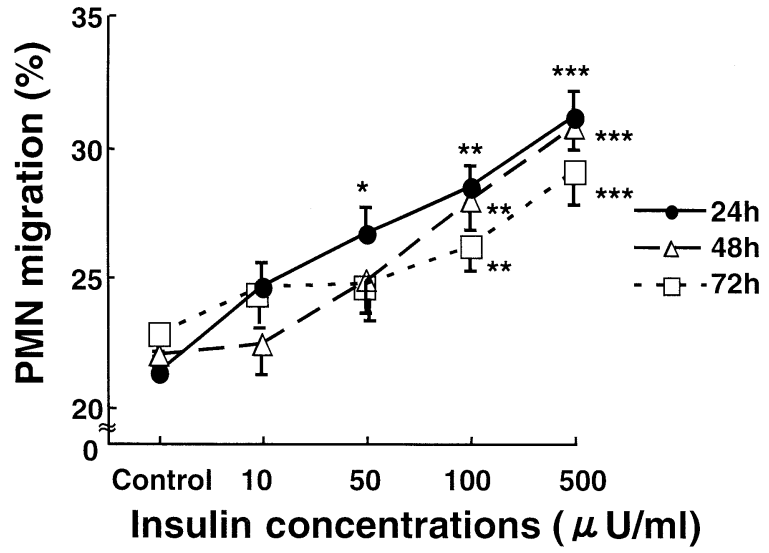

Fig. 1. Effect of high insulin on PMN migration across HUVEC. Cells were treated without (control) or with insulin at doses ranging from 10 to $500 \mu \mathrm{U} / \mathrm{ml}$ for 24,48 , and $72 \mathrm{~h}$. Values are expressed as means \pm SEM. $* p<0.05, * * p<0.01$, $* * * p<0.001$ compared to respective control

\section{Results}

Effect of high insulin on PMN migration across $H U V E C$. To establish the optimum concentration of insulin for stimulating PMN migration across HUVEC monolayers, dose-response and time-response experiments were carried out. HUVEC monolayers were incubated for 24 to $72 \mathrm{~h}$ with human regular insulin at doses from 10 to $500 \mu \mathrm{U} / \mathrm{ml}(0.0609$ to $3.05 \mathrm{nmol} / \mathrm{l})$. Insulin concentrations over $50 \mu \mathrm{U} / \mathrm{ml}(0.305 \mathrm{nmol} / \mathrm{l})$ for $24 \mathrm{~h}$ or $100 \mu \mathrm{U} / \mathrm{ml}(0.609 \mathrm{nmol} / \mathrm{l})$ for 48 to $72 \mathrm{~h}$ increased the migration of PMN obtained from healthy subjects in a dose-dependent (but not time-dependent) manner (Fig. 1). The effects of high insulin reached a maximum at $24 \mathrm{~h}$. In addition, the migration of PMN from diabetic patients $(n=4)$ with hyperinsulinaemia through HUVEC incubated with $100 \mu \mathrm{U} / \mathrm{ml}$ insulin for $24 \mathrm{~h}$ was increased compared with that from healthy subjects (healthy subjects: $28.2 \pm 0.7 \%$; diabetic pa-

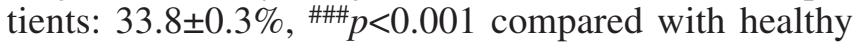
subjects). The average insulin concentration of these diabetic patients was $107.3 \pm 7.5 \mu \mathrm{U} / \mathrm{ml}$. Next, we examined whether high insulin concentrations promote endothelial cell proliferation and found that endothelial cell counts did not change after treatment with $100 \mu \mathrm{U} / \mathrm{ml}$ insulin for 24 to $72 \mathrm{~h}$.

Effect of high insulin on surface expression of endothelial PECAM-1. We then evaluated whether high insulin influences the surface expression of the endothelial adhesion molecule, PECAM-1, and found that it was increased by incubating HUVEC with $100 \mu \mathrm{U} / \mathrm{ml}$ insulin only for $24 \mathrm{~h}$ (Fig. 2). Since PMN migration across HUVEC and PECAM-1 expression mediated by high insulin reached their peaks at $24 \mathrm{~h}$, in further experiments endothelial cells were incubated with $100 \mu \mathrm{U} / \mathrm{ml}$ insulin for $24 \mathrm{~h}$. 


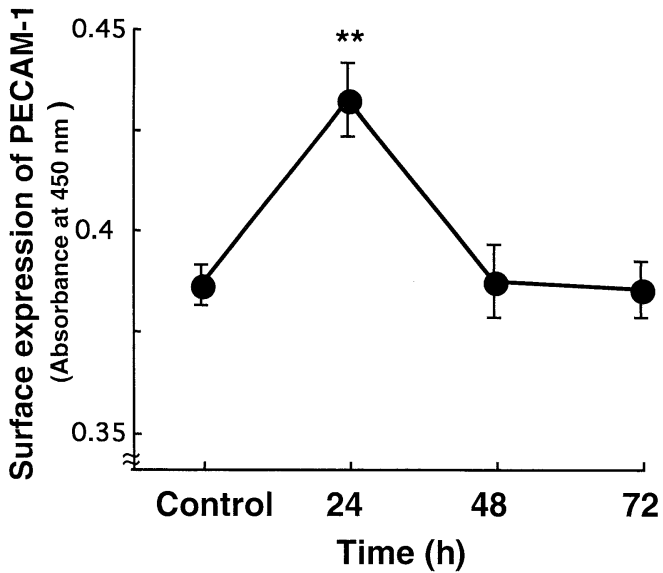

Fig. 2. Effect of high insulin on surface expression of endothelial PECAM-1. Cells were treated without (control) or with $100 \mu \mathrm{U} / \mathrm{ml}$ insulin for 24, 48, and $72 \mathrm{~h}$. Values are expressed as means \pm SEM. $* * p<0.01$ compared to control

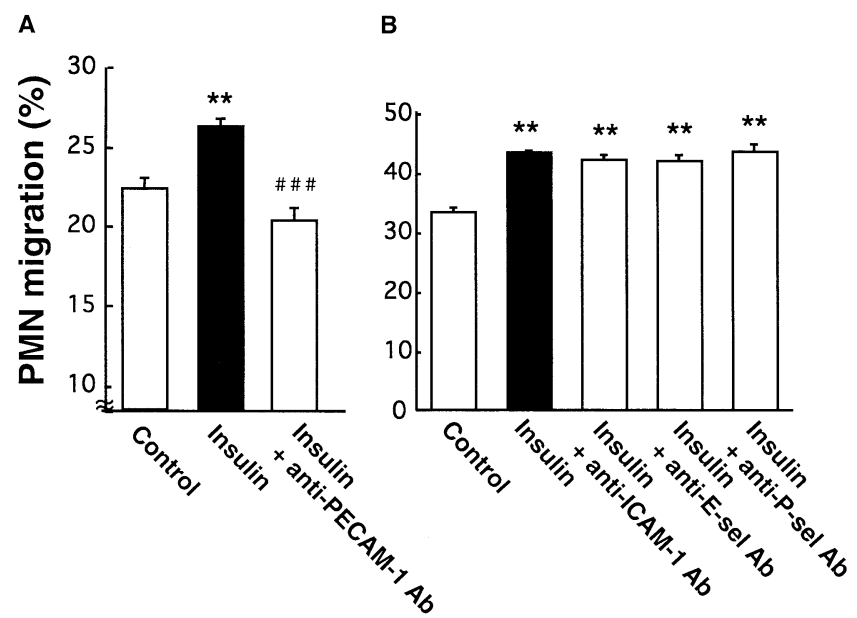

Fig. 3A, B. Effects of antibodies for endothelial adhesion molecules on the high insulin-mediated PMN migration. Cells were treated without (control) or with $100 \mu \mathrm{U} / \mathrm{ml}$ insulin for $24 \mathrm{~h}$ (insulin) in the presence or absence of $10 \mu \mathrm{g} / \mathrm{ml}$ antiPECAM-1 (A), anti-ICAM-1 (B), anti-P-selectin (B), and antiE-selectin antibody (B). Values are expressed as means \pm SEM. $* * p<0.01$ compared to respective control. \#\#\# $p<0.001$ compared to the cells treated with high insulin alone

Addition of an antibody (Ab) specific for PECAM-1 $(10 \mu \mathrm{g} / \mathrm{ml})$ during the migration assay attenuated the enhanced PMN migration across HUVEC mediated by $100 \mu \mathrm{U} / \mathrm{ml}$ insulin for $24 \mathrm{~h}$ (Fig. 3A), whereas antiICAM-1 Ab, anti-E-selectin $\mathrm{Ab}$ and anti-P-selectin $\mathrm{Ab}(10 \mu \mathrm{g} / \mathrm{ml})$ did not affect the migration (Fig. 3B). These results show a correlation between high insulinmediated PMN migration and over-expression of endothelial PECAM-1 but not of ICAM-1, E-selectin or P-selectin.

Effect of high insulin on endothelial PECAM-1 phosphorylation. To assess why PMN migration mediated by high insulin was increased without enhancing
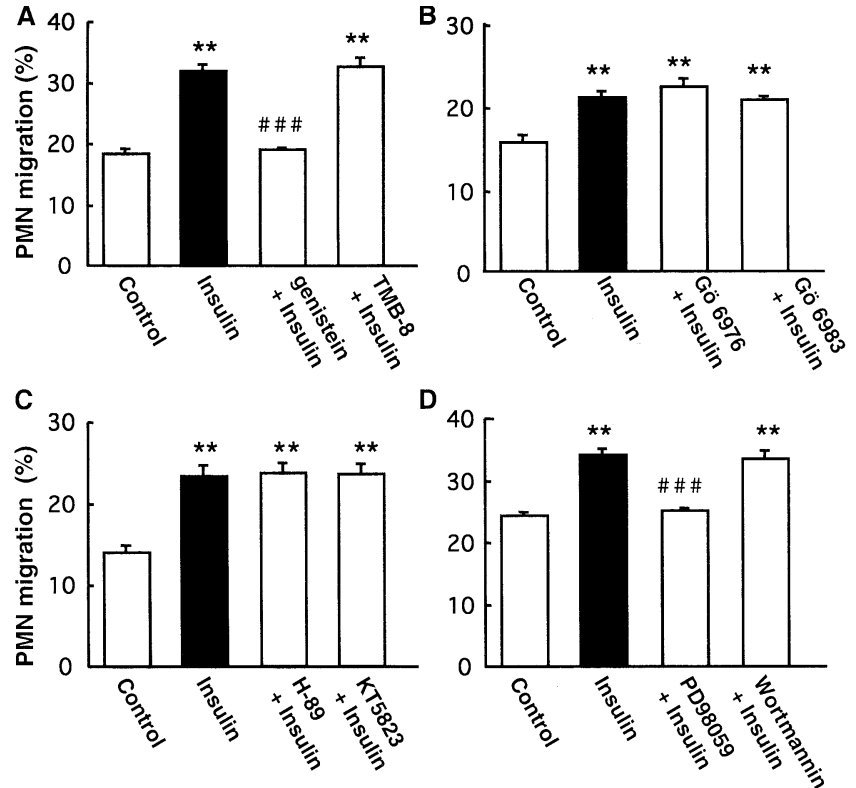

Fig. 4A-D. Effects of intracellular second messenger inhibitors on the high insulin-mediated PMN migration across HUVEC mediated by high insulin. Cells were treated without (control) or with $100 \mu \mathrm{U} / \mathrm{ml}$ insulin for $24 \mathrm{~h}$ (insulin) in the presence or absence of a tyrosine kinase inhibitor, $5 \mu \mathrm{mol} / 1$ genistein (A), an intracellular calcium chelator, $0.1 \mathrm{mmol} / \mathrm{l}$ TMB-8 (A), a classical PKC inhibitor, 10 nmol/l Gö6976 (B), a broad PKC inhibitor, $0.1 \mu \mathrm{mol} / 1$ Gö6983 (B), a PKA inhibitor, $0.1 \mu \mathrm{mol} / 1 \mathrm{H}-89$ (C), a PKG inhibitor, $0.5 \mu \mathrm{mol} / \mathrm{l} \mathrm{KT5823}$ (C), a MAP kinase inhibitor, $10 \mu \mathrm{mol} / \mathrm{l} \mathrm{PD98059}$ (D), and a PI-3 kinase inhibitor, $10 \mathrm{nmol} / 1$ wortmannin (D). Values are expressed as means \pm SEM. $* * p<0.01$ compared to respective control, ${ }^{\# \#} p<0.001$ compared to the cells treated with high insulin alone

PECAM-1 surface expression after $48 \mathrm{~h}$, we analysed the change of PECAM-1 phosphorylation of HUVEC at different time points using a Western blotting method. However, in this study, we did not detect PECAM-1 phosphorylation at any points in cells treated with or without $100 \mu \mathrm{U} / \mathrm{ml}$ insulin until $72 \mathrm{~h}$, suggesting that PECAM-1 phosphorylation was irrelevant to the increased PMN migration.

Effects of intracellular second messenger inhibitors on the high insulin-mediated PMN migration and PECAM-1 expression. We attempted to define the signal transduction pathways involved in the enhanced PMN migration mediated by high insulin. The enhanced migration caused by $100 \mu \mathrm{U} / \mathrm{ml}$ insulin for $24 \mathrm{~h}$ was attenuated by a tyrosine kinase inhibitor, genistein $(5 \mu \mathrm{mol} / \mathrm{l})$ (Fig. 4A), but not by a classic PKC inhibitor, Gö6976 (10 nmol/l) (Fig. 4B), a broad PKC inhibitor, Gö6983 (0.1 $\mu \mathrm{mol} / \mathrm{l})$, a PKA inhibitor, H-89 (0.1 $\mu \mathrm{mol} / \mathrm{l})$ (Fig. 4C), a PKG inhibitor, KT5823 $(0.5 \mu \mathrm{mol} / \mathrm{l})$, or an intracellular calcium chelator, TMB-8 (0.1 mmol/l) (Fig. 4A).

We also examined the participation of two insulin receptor-mediated tyrosine kinases, MAP kinase and 


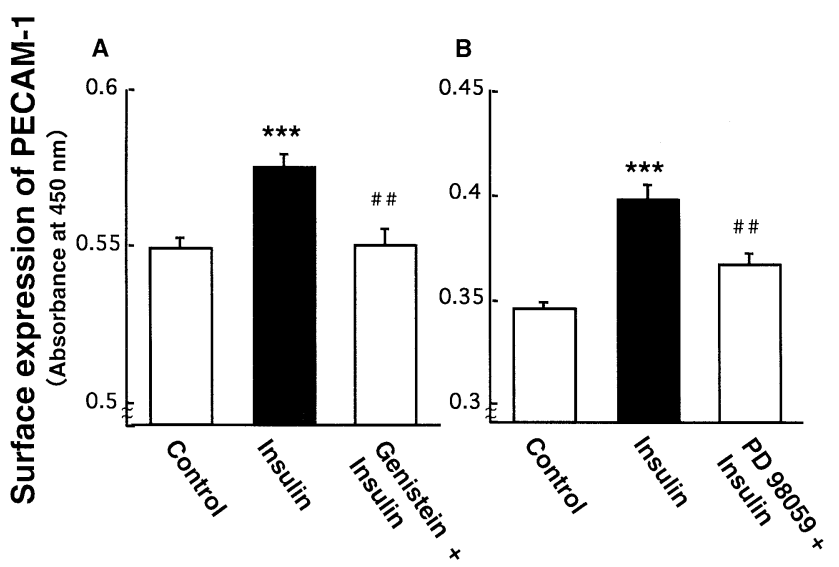

Fig. 5A, B. Effects of tyrosine kinase inhibitors on the high insulin-mediated PECAM-1 expression. Cells were treated without (control) or with $100 \mu \mathrm{U} / \mathrm{ml}$ insulin for $24 \mathrm{~h}$ (insulin) in the presence or absence of a tyrosine kinase inhibitor, $5 \mu \mathrm{mol} / \mathrm{l}$ genistein (A), and a MAP kinase inhibitor, $10 \mu \mathrm{mol} / 1$ PD98059 (B). Values are expressed as means \pm SEM. $* * * p<0.001$ compared to respective control, ${ }^{\#} p<0.01$ compared to the cells treated with high insulin alone

PI-3 kinase, in the action of high insulin on PMN migration, and found that a MAP kinase inhibitor, PD98059 $(10 \mu \mathrm{mol} / \mathrm{l})$, but not a PI-3 kinase inhibitor, wortmannin $(10 \mathrm{nmol} / \mathrm{l})$, attenuated the effect of high insulin (Fig. 4D).

The enhanced expression of endothelial PECAM-1 caused by $100 \mu \mathrm{U} / \mathrm{ml}$ insulin for $24 \mathrm{~h}$ was also inhibited by the tyrosine kinase inhibitor, genistein $(5 \mu \mathrm{mol} / \mathrm{l})$ (Fig. 5A) and the MAP kinase inhibitor, PD98059 (10 $\mu \mathrm{mol} / \mathrm{l})$ (Fig. 5B).

Participation of MAP kinase activation in PMN migration and endothelial PECAM-1 expression. To confirm the participation of MAP kinase activation in both PMN migration and endothelial PECAM-1 expression, we examined the effects of a MAP kinase activator, anisomycin. Anisomycin, in concentrations over $1 \mu \mathrm{mol} / \mathrm{l}$, by itself increased PMN migration and in concentrations over $0.1 \mu \mathrm{mol} / 1$ enhanced surface expression of endothelial PECAM-1 within $3 \mathrm{~h}$ in a dose-dependent manner (Fig. 6A, B), suggesting the involvement of MAP kinase in these phenomena.

Effects of NOS inhibitors on the enhanced PMN migration across HUVEC mediated by high insulin. To see if there is a relation between nitric oxide and the enhanced PMN transendothelial migration caused by high insulin, we examined the effects of two NOS inhibitors, an endothelial NOS inhibitor, L-NAME $(30 \mu \mathrm{mol} / \mathrm{l})$ and an inhibitor of inducible NOS, L-NIO ( $3 \mu \mathrm{mol} / \mathrm{l})$. These NOS inhibitors did not affect the enhanced PMN migration mediated by $100 \mu \mathrm{U} / \mathrm{ml}$ insulin for $24 \mathrm{~h}$ (control: 33.5 $\pm 0.5 \%$; high insulin: 45.2 $\pm 0.8 \%$; high insulin + L-NAME: $44.3 \pm 0.9 \%$; high insulin + L-NIO: $46.3 \pm 1.1 \%$ ), suggesting that at least
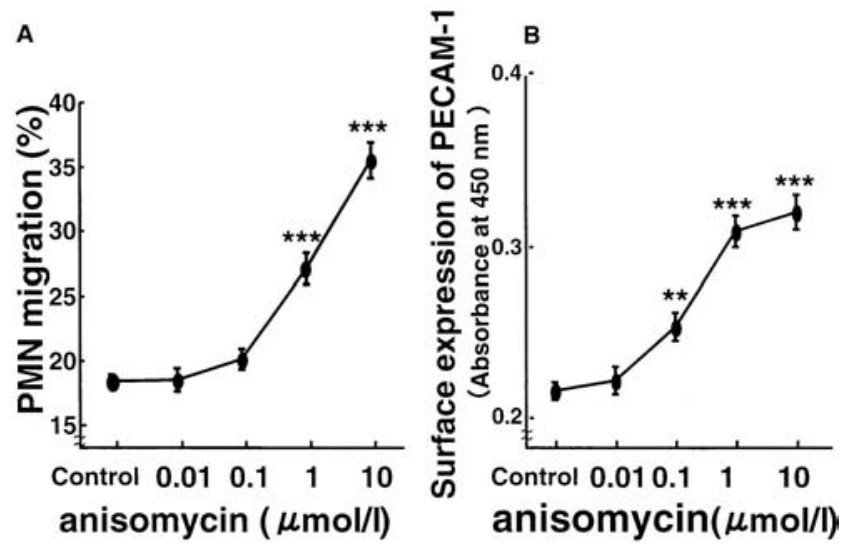

Fig. 6A, B. Effects of a MAP kinase activator, anisomycin on PMN migration (A) and endothelial PECAM-1 expression (B). Cells were treated without (control) or with anisomycin at doses ranging from 0.01 to $10 \mu \mathrm{mol} / 1$ for $3 \mathrm{~h}$. Values are expressed as means \pm SEM. $* * p<0.01, * * * p<0.001$ compared to respective control

endogeneous nitric oxide was not involved in this phenomenon.

\section{Discussion}

We found evidence for the direct atherogenic actions of high insulin, which at concentrations over $50 \mu \mathrm{U} / \mathrm{ml}$ for $24 \mathrm{~h}$ or $100 \mu \mathrm{U} / \mathrm{ml}$ for 48 to $72 \mathrm{~h}$, significantly enhanced neutrophil transendothelial migration in a dose-dependent manner. In addition, endothelial migration of PMN obtained from diabetic patients with hyperinsulinaemia was also increased compared with that from healthy subjects. The PMN transendothelial migration enhanced by high insulin might account for the high incidence of atherosclerotic diseases such as AMI and stroke in patients with diabetes, because PMN transendothelial migration seems to contribute to the formation of atherosclerotic plaques and their disruption $[4,13]$. There is growing evidence supporting a close relation between atherosclerosis and PMN activation and migration [11, 12, 22, 23, 24, 25, 26, 27]. Firstly, atherosclerosis has been reported to be characterized by monocyte infiltration which can be mediated by the neutrophil-induced release of endothelial monocyte-chemoattractant protein-1 [22]. Secondly, some investigators suggested that the activity of MPO, which is an enzyme from leukocytes including neutrophils, was correlated with the presence of AMI, and MPO itself was present in atherosclerotic plaques $[12,23]$. Thirdly, recent reports indicated that neutrophils are occasionally found in disrupted plaques and also that they migrate into the arterial wall shortly after ischaemia-reperfusion [11, 24]. Apoptosis of neutrophils after their transendothelial mi- 
gration seems to be crucial for the progression of atherosclerotic plaques because their delayed apoptosis after migration results in the maintenance of oxygen radicals and chemoattractant release leading to enhanced cytotoxicity and subsequent tissue damage, that predispose to cause plaque disruption $[25,26$, 27].

Since PMN transendothelial migration is modulated by endothelial adhesion molecules, especially by PECAM-1 [14, 15], we hypothesized that the enhanced migration caused by high insulin was secondary to the induction of the adhesion molecule on insulin-activated endothelial cells. We found that the enhanced PMN migration observed for $24 \mathrm{~h}$ of incubation with high insulin $(100 \mu \mathrm{U} / \mathrm{ml})$ was associated with a concomitant increase in the expression of endothelial PECAM-1. The involvement of endothelial PECAM-1 in insulin-enhanced PMN migration was confirmed by showing that it was inhibited by an anti-PECAM-1 Ab but not by an anti-ICAM-1, anti-Pselectin or anti-E-selectin Ab. We reported previously that high insulin increased endothelial ICAM-1 expression leading to enhanced neutrophil-endothelial cell adhesion [20]; however, it is not likely that ICAM-1 expression is correlated with PMN transendothelial migration. We found that high insulin directly enhanced endothelial PECAM-1 expression leading to increased PMN transendothelial migration, whereas many reports have indicated that surface expression of endothelial PECAM-1 is not altered by inflammatory mediators [14, 28]. Conversely, ICAM-1 and E-selectin were reported to have roles in transendothelial migration of lymphocytes and eosinophils $[29,30]$.

The question arises as to why the high insulinmediated PMN migration increased until $72 \mathrm{~h}$ while endothelial PECAM-1 surface expression was enhanced only within $24 \mathrm{~h}$. We hypothesized that the increased PMN migration after $48 \mathrm{~h}$ in our model could be attributed mainly to enhanced PECAM-1 phosphorylation but not to the increase in its surface expression, since previous studies suggested that enhanced PECAM-1 phosphorylation without enhanced endothelial PECAM-1 expression could increase PMN migration [31, 32]. However, in this study, we found that PECAM-1 phosphorylation was not enhanced at any points in cells treated with or without $100 \mu \mathrm{U} / \mathrm{ml}$ insulin until $72 \mathrm{~h}$, suggesting that PECAM-1 phosphorylation was irrelevant to the increased PMN migration. Therefore, it is possible that PMN migration enhanced by high insulin after $48 \mathrm{~h}$ is correlated with another mechanism. In addition to PECAM-1, leukocyte transmigration has been reported to be modulated by some junctional proteins between endothelial cells such as vascular endothelial (VE)-cadherin, junctional adhesion molecule (JAM)-1 and CD 99 [33, 34, 35]. Another study indicated that reactive oxygen species (ROS) such as hydrogen peroxide are involved in
PECAM-1-dependent leukocyte transmigration [31, $32,36]$. In this regard, a possible explanation of the discrepancy between PMN migration and PECAM-1 expression data after $48 \mathrm{~h}$ is that high insulin might enhance PMN migration affecting such junctional proteins or ROS. Therefore, further experiments in this study used only cells incubated with $100 \mu \mathrm{U} / \mathrm{ml}$ insulin for $24 \mathrm{~h}$.

We then investigated the intracellular signal transduction pathways which could be involved in the enhanced PMN migration and endothelial PECAM-1 expression mediated by high insulin. Of the second messenger inhibitors tested, only a tyrosine kinase inhibitor, genistein, attenuated the effects of high insulin, suggesting the involvement of this pathway in our model. We further evaluated the correlation of insulin receptor-mediated two tyrosine kinases, MAP and PI-3, with the insulin-mediated enhanced PMN migration and endothelial PECAM-1 expression, because it has been reported that an imbalance between these two pathways in diabetes could be the cause of accelerated atherosclerosis in patients with diabetes [37]. We found that both the high insulin-mediated PMN migration and endothelial expression were attenuated by pretreatment with the MAP kinase inhibitor, PD98059, but not with the PI 3-kinase inhibitor, wortmannin. In addition, a MAP kinase activator, anisomycin, by itself increased both PMN migration and endothelial PECAM-1 expression. These findings strongly suggest that high insulin enhances both events via activation of a MAP kinase pathway. Although little is known about the intracellular mechanisms responsible for high insulin-mediated PMN migration, previous studies demonstrating that insulin promotes vascular smooth muscle cell migration leading to acceleration of atherosclerosis through tyrosine kinase activity, particularly that of MAP kinase, might support our results [38, 39]. In addition, consistent with our data, a recent study suggested the involvement of MAP kinase signalling in monocyte migration, because transmigration of monocytes mediated by monocyte chemoattractant protein (MCP)-1 was attenuated by PD98059 [9].

Although a normal concentration of insulin induces endothelium-derived nitric oxide [40], which is one of the most important anti-inflammatory mediators, this is reported to be blunted in insulin resistance [41, 42]. This is caused by decreased synthesis of nitric oxide from the endothelium and along with the insensitivity of vascular endothelial cells to nitric oxide results in the promotion of vascular inflammation $[43,44]$. We therefore examined the correlation between nitric oxide and the enhanced PMN migration mediated by high insulin by using NOS inhibitors. However, the addition of two different NOS inhibitors, L-NAME and L-NIO, did not modify the results, suggesting that at least endogenous nitric oxide did not participate in the high insulin-mediated effects. 
Our study clarifies the direct atherogenic action of high insulin on the endothelium which involves enhanced neutrophil transendothelial migration through an increase in surface expression of endothelial PECAM-1. These phenomena are mediated by activation of a tyrosine kinase pathway, especially MAP kinase, without the participation of endogenous nitric oxide. These results should facilitate the development of better pharmacologic agents to prevent vascular complications in patients with diabetes, particularly those with hyperinsulinaemia.

\section{References}

1. Stout RW (1996) Hyperinsulinemia and atherosclerosis. Diabetes 45 [Suppl 3]: S45-S46

2. Standl E (1995) Hyperinsulinemia and atherosclerosis. Clin Invest Med 18: 261-266

3. Pyorala M, Miettinen H, Laakso M, Pyorala K (1998) Hyperinsulinemia predicts coronary heart disease risk in healthy middle-aged men: the 22-year follow-up results of the Helsinki Policemen Study. Circulation 98: 398-404

4. Falk E, Shah PK, Fuster V (1995) Coronary plaque disruption. Circulation 92: 657-671

5. Rattan V, Shen Y, Sultana C, Kumar D, Kalra VK (1996) Glucose-induced transmigration of monocytes is linked to phosphorylation of PECAM-1 in cultured endothelial cells. Am J Physiol 271: E711-E717

6. UK Prospective Diabetes Study (UKPDS) Group (1998) Intensive blood-glucose control with sulphonylureas or insulin compared with conventional treatment and risk of complications in patients with type 2 diabetes (UKPDS 33). Lancet 352: 837-853

7. Cerveny JD, Leder RD, Weart CW (1998) Issues surrounding tight glycemic control in people with type 2 diabetes mellitus. Ann Pharmacother 32: 896-905

8. Ohkubo Y, Kishikawa H, Araki E et al. (1995) Intensive insulin therapy prevents the progression of diabetic microvascular complications in Japanese patients with non-insulin-dependent diabetes mellitus: a randomized prospective 6-year study. Diabetes Res Clin Pract 28: 103-117

9. Ross R (1999) Atherosclerosis is an inflammatory disease. Am Heart J 138: S419-S420

10. Wetzler C, Kampfer H, Stallmeyer B, Pfeilschifter J, Frank S (2000) Large and sustained induction of chemokines during impaired wound healing in the genetically diabetic mouse: prolonged persistence of neutrophils and macrophages during the late phase of repair. J Invest Dermatol 115: 245-253

11. Wal AC van der, Becker AE, Loos CM van der, Das PK (1994) Site of intimal rupture or erosion of thrombosed coronary atherosclerotic plaques is characterized by an inflammatory process irrespective of the dominant plaque morphology. Circulation 89: 36-44

12. Brennan ML, Anderson MM, Shih DM et al. (2001) Increased atherosclerosis in myeloperoxidase-deficient mice. J Clin Invest 107: 419-430

13. Dunzendorfer S, Rothbucher D, Schratzberger P, Reinisch N, Kahler CM, Wiedermann CJ (1997) Mevalonate-dependent inhibition of transendothelial migration and chemotaxis of human peripheral blood neutrophils by pravastatin. Circ Res 81: 963-969

14. Christofidou-Solomidou M, Nakada MT, Williams J, Muller WA, DeLisser HM (1997) Neutrophil platelet endo- thelial cell adhesion molecule-1 participates in neutrophil recruitment at inflammatory sites and is down-regulated after leukocyte extravasation. J Immunol 158: 4872-4878

15. Bogen S, Pak J, Garifallou M, Deng X, Muller WA (1994) Monoclonal antibody to murine PECAM-1 (CD31) blocks acute inflammation in vivo. J Exp Med 179: 1059-1064

16. Thompson RD, Noble KE, Larbi KY et al. (2001) Plateletendothelial cell adhesion molecule-1 (PECAM-1)-deficient mice demonstrate a transient and cytokine-specific role for PECAM-1 in leukocyte migration through the perivascular basement membrane. Blood 97: 1854-1860

17. Hsueh WA, Law RE (1999) Insulin signaling in the arterial wall. Am J Cardiol 84: 21J-24J

18. Xi XP, Graf K, Goetze S, Hsueh WA, Law RE (1997) Inhibition of MAP kinase blocks insulin-mediated DNA synthesis and transcriptional activation of c-fos by Elk-1 in vascular smooth muscle cells. FEBS Lett 417: 283-286

19. Baron AD (1999) Vascular reactivity. Am J Cardiol 84: 25J-27J

20. Okouchi M, Okayama N, Shimizu M, Omi H, Fukutomi T, Itoh M (2002) High insulin exacerbates neutrophil-endothelial cell adhesion through increasing endothelial surface expression of intercellular adhesion molecule-1 via activation of protein kinase $\mathrm{C}$ and mitogen activated protein kinase. Diabetologia 45 (in press)

21. Ohno N, Ichikawa H, Coe L, Kvietys PR, Granger DN, Alexander JS (1997) Soluble selectins and ICAM-1 modulate neutrophil-endothelial adhesion and diapedesis in vitro. Inflammation 21: 313-324

22. Schratzberger P, Dunzendorfer S, Reinisch N, Kahler CM, Herold M, Wiedermann CJ (1998) Release of chemoattractants for human monocytes from endothelial cells by interaction with neutrophils. Cardiovasc Res 38: 516-521

23. Zhang R, Brennan ML, Fu X et al. (2001) Association between myeloperoxidase levels and risk of coronary artery disease. JAMA 286: 2136-2142

24. Kloner RA, Giacomelli F, Alker KJ, Hale SL, Matthews R, Bellows S (1991) Influx of neutrophils into the walls of large epicardial coronary arteries in response to ischemia/reperfusion. Circulation 84: 1758-1772

25. Klein JB, Rane MJ, Scherzer JA et al. (2000) Granulocytemacrophage colony-stimulating factor delays neutrophil constitutive apoptosis through phosphoinositide 3-kinase and extracellular signal-regulated kinase pathways. J Immunol 164: 4286-4291

26. Watson RW, Rotstein OD, Nathens AB, Parodo J, Marshall JC (1997) Neutrophil apoptosis is modulated by endothelial transmigration and adhesion molecule engagement. J Immunol 158: 945-953

27. Kaneider NC, Reinisch CM, Dunzendorfer S, Meierhofer C, Djanani A, Wiedermann CJ (2001) Induction of apoptosis and inhibition of migration of inflammatory and vascular wall cells by cerivastatin. Atherosclerosis 158: 23-33

28. Allport JR, Ding H, Collins T, Gerritsen ME, Luscinskas FW (1997) Endothelial-dependent mechanisms regulate leukocyte transmigration: a process involving the proteasome and disruption of the vascular endothelial-cadherin complex at endothelial cell-to-cell junctions. J Exp Med 186: 517-527

29. Oppenheimer-Marks N, Davis LS, Bogue DT, Ramberg J, Lipsky PE (1991) Differential utilization of ICAM-1 and VCAM-1 during the adhesion and transendothelial migration of human T lymphocytes. J Immunol 147: 2913-2921

30. Ebisawa M, Bochner BS, Georas SN, Schleimer RP (1992) Eosinophil transendothelial migration induced by cytokines. I. Role of endothelial and eosinophil adhesion molecules in IL-1 beta-induced transendothelial migration. J Immunol 149: 4021-4028 
31. Rattan V, Sultana C, Shen Y, Kalra VK (1997) Oxidant stress-induced transendothelial migration of monocytes is linked to phosphorylation of PECAM-1. Am J Physiol 273: E453-E461

32. Rattan V, Shen Y, Sultana C, Kumar D, Kalra VK (1997) Diabetic RBC-induced oxidant stress leads to transendothelial migration of monocyte-like HL-60 cells. Am J Physiol 273: E369-E375

33. Dejana E, Spagnuolo R, Bazzoni G. (2001) Interendothelial junctions and their role in the control of angiogenesis, vascular permeability and leukocyte transmigration. Thromb Haemost 86: 308-315

34. Gotsch U, Borges E, Bosse R et al. (1997) VE-cadherin antibody accelerates neutrophil recruitment in vivo. J Cell Sci 110: 583-588

35. Schenkel AR, Mamdouh Z, Chen X, Liebman RM, Muller WA. (2002) CD99 plays a major role in the migration of monocytes through endothelial junctions. Nat Immunol 3: 143-150

36. Scalia R, Lefer AM (1998) In vivo regulation of PECAM-1 activity during acute endothelial dysfunction in the rat mesenteric microvasculature. J Leukoc Biol 64: 163-169

37. Hsueh WA, Law RE (1998) Cardiovascular risk continuum: implications of insulin resistance and diabetes. Am J Med 105: 4S-14S
38. Liu W, Liu Y, Lowe WL Jr (2001) The role of phosphatidylinositol 3-kinase and the mitogen-activated protein kinases in insulin-like growth factor-I-mediated effects in vascular endothelial cells. Endocrinology 142: 1710-1719

39. Ikeo S, Yamauchi K, Shigematsu S, Nakajima K, Aizawa T, Hashizume K. (2001) Differential effects of growth hormone and insulin-like growth factor I on human endothelial cell migration. Am J Physiol Cell Physiol 280: C1255C1261

40. Pryor WA, Squadrito GL (1995) The chemistry of peroxynitrite: a product from the reaction of nitric oxide with superoxide. Am J Physiol 268: L699-L722

41. Laakso M, Edelman SV, Brechtel G, Baron AD (1992) Impaired insulin-mediated skeletal muscle blood flow in patients with NIDDM. Diabetes 41: 1076-1083

42. Walker AB, Dores J, Buckingham RE, Savage MW, Williams G (1997) Impaired insulin-induced attenuation of noradrenaline-mediated vasoconstriction in insulin-resistant obese Zucker rats. Clin Sci (Colch) 93: 235-241

43. Munzel T, Heitzer T, Harrison DG (1997) The physiology and pathophysiology of the nitric oxide/superoxide system. Herz Jun 22: 158-172

44. Busse R, Fleming I (1996) Endothelial dysfunction in atherosclerosis. J Vasc Res 33: 181-194 